This item was submitted to Loughborough's Research Repository by the author.

Items in Figshare are protected by copyright, with all rights reserved, unless otherwise indicated.

\title{
Do relational goods raise well-being? An econometric analysis
}

PLEASE CITE THE PUBLISHED VERSION

http://dx.doi.org/10.1057/eej.2015.46

\section{PUBLISHER}

(c) Palgrave Macmillan

\section{VERSION}

AM (Accepted Manuscript)

\section{PUBLISHER STATEMENT}

This work is made available according to the conditions of the Creative Commons Attribution-NonCommercialNoDerivatives 4.0 International (CC BY-NC-ND 4.0) licence. Full details of this licence are available at: https://creativecommons.org/licenses/by-nc-nd/4.0/

\section{LICENCE}

CC BY-NC-ND 4.0

\section{REPOSITORY RECORD}

Rasciute, Simona, Paul M. Downward, and William Greene. 2019. "Do Relational Goods Raise Well-being? an Econometric Analysis". figshare. https://hdl.handle.net/2134/17293. 


\begin{tabular}{|c|c|c|}
\hline Dr Paul Downward & Professor William Green & Dr Simona Rasciute \\
School of Sport and Exercise & School of Business and \\
Sciences & Economics \\
Loughborough University & Departer & Loughbont of Economics \\
Leicestershire & 44 West Fourth Street, 7-90 & Leicestershire \\
LE11 3TU & New York, NY 10012 \\
USA & LE11 3TU \\
+44 (0)1509 226365 & (212) 998-0876 & +44 (0)1509 223620 \\
p.downward@lboro.ac.uk & wgreene@stern.nyu.edu & s.rasciute@lboro.ac.uk \\
\hline
\end{tabular}

\title{
DO RELATIONAL GOODS RAISE WELL-BEING? AN ECONOMETRIC ANALYSIS
}

\begin{abstract}
This paper explores the relationship between different types of relational goods and well-being and examines if there is latent/unobserved heterogeneity in this relationship by applying the Latent Class Ordered Probit model. This unique contribution to the literature examines if some individuals have a more associative disposition than others which contributes to their subjective well-being through the consumption of relational goods. As well as relational goods that have been well researched, such as marital status and household composition, this paper explores participation in sports, arts and cultural activities, as well as attendance at events or facilities for these activities, heritage visits, volunteering and gambling.
\end{abstract}

JEL Classification: C25, I31, D31, J12

Keywords: Relational goods, social interactions, Latent Class Ordered Probit model, unobserved/latent heterogeneity 


\section{INTRODUCTION}

There has been historical variation in the treatment by economists of the role and importance of social interactions to the functioning of economies and to the welfare of economic agents. Manski [2000], for example, notes that there has been a traditional narrow view, in which economics primarily studies the interactions of agents through impersonal and anonymous mechanisms such as markets. In contrast, more recently a broader view has emerged in which resource allocation is examined through a focus on how agents respond to association and experience [Gui, 2000]. One important dimension of Gui's [2000] analysis is that social interactions can be associated with the production of relational goods these are the affective, non-instrumental and experiential dimension of activities. They might be associated with companionship, approval, shared experience, recognition by others and so on. Typically they might arise in family and friendship groupings, but also in social events such as club meetings, or collective consumption of events or activities [Becchetti et al. 2008].

This raises three issues which are central to this research. The first is that both formal and informal associations connected with social and recreational activities and events can have a relational character. The second is that, if engagement in these activities is viewed as the outcome of rational deliberation, the social interactions implied in their consumption as relational goods can be expected to enhance the subjective well-being of individuals. Traditional measures of welfare, that emphasise the material and impersonal elements of economics transactions, such as the payment of fees or the outlay of expenditures may not capture these features. The third issue is that because social interactions reflect the context of the experience then one might also expect that different dispositions of individuals, for example towards collective consumption experiences, means that consumption of any goods described 
as relational may affect well-being differently for individuals. In other words there could be heterogeneity in the relationships between experience of an activity and subjective well-being. One cannot simply assume that a single (average) relationship exists across individuals.

The aim of this paper, therefore, is to examine the heterogeneity of association between various activities that could be described as relational goods and the subjective well-being of economic agents, but particularly to focus on those goods that emanate from social, sporting, arts and cultural aspects of life. To achieve this aim ordered choice models are employed on a unique dataset from England. The main contribution of the paper to the literature is to account for the likely observed and unobserved heterogeneity of the relationships, which has not been examined before, as it is hypothesised that different types of individuals might be identified who despite being engaged in the same behaviours might be grouped differently according to the association of their behaviour with subjective well-being. A novel component of the paper, therefore, is the application of a latent class ordered choice model to explore unobserved individual heterogeneity. The main results of the paper suggest that in accord with the literature, certain activities are associated with enhanced individual subjective well-being but there is heterogeneity in the relationships. Further, it is shown that these differential associations between activity and well-being also depend on unobserved factors, which this paper attributes to being reflective of an unobserved relational rather than instrumental disposition. One consequence of this investigation is that the paper has an exploratory emphasis in seeking to identify if such heterogeneity exists and to suggest what might account for it, which the literature currently does not address. In consequence there is no attempt to make causal claims.

The paper proceeds as follows. In Section 2, a brief review of the literature on social interactions and relational goods is provided. The existing research on the impact of relational goods on subjective wellbeing is also presented. This includes discussion of results that could be linked to relational goods, but is not actually made explicit or interpreted as such, and also the research that explicitly accounts for 
their impact. Section 3 outlines the data and variables. Section 4 presents the econometric models used in the analysis. Section 5 presents the main results of the research and Section 6 concludes the paper.

\section{LITERATURE REVIEW}

\section{$\underline{\text { Social Interactions and Relational Goods }}$}

The economics literature has increasingly analysed social interactions. Manski [2000] argues that there are three major mechanisms by which this occurs. The most traditional format has been through the expectations of agents. Naturally this has played a huge role in macroeconomics embracing both adaptive and rational expectations [Lucas, 1976] or other expectation formation systems associated with, for example, bounded rationality and rules of thumb in behaviour [Cyert and March, 1963] or decision heuristics [Tverskey and Kahneman, 1974]. These have subsequently been incorporated in the study of the origin and efficiency of institutions through transaction cost economics, the microeconomics of decision making under risk and uncertainty generally, and behavioural finance. The other two forms of interaction are essentially connected with welfare economics and the externalities that are mediated across agents either via the constraints that they face or through the direct spilling over of utility between agents [Becker, 1974; Cauley and Sandler, 1980; Cornes and Sandler, 1986]. Finally as Manski [1993; 2000] notes, in essence the whole development of game theory that now dominates microeconomics suggests that social interactions are, at least implicitly, central to economic analysis. This is because agent optimisation has to account for endogenous effects arising from the feedback from more aggregate behaviour to that of individuals. This latter perspective, of course, suggests that the mechanisms by which social interactions operate, that is through utility or constraints, is of less significance than the fact that they can be recognised as taking place but in different forms.

More recently, the literature has begun to refine, and to an extent challenge, this understanding of social interactions. There are two related dimensions to this. The first is that it can be argued that there is something essentially different about social interactions than the usual economic analysis of 
externalities. Consequently, whilst Gui [2000, p152] finds strong parallels between relational goods as the produced outputs of consumer-producers in household production [Becker, 1965], and by implication social interactions [Becker, 1974], or more generally club goods [Cornes and Sandler, 1986], it can also be argued that in economic analysis it remains that there has been a tendency to treat relational goods as inherently private goods. In this case the individual accounts for the social in their decision making only in as much that individuals extract private returns by internalising externalities. In contrast, the links between the private and public goods aspects of the relational goods, that is the interpersonal level, is ignored. The interpersonal dimension is something that emerges from the individual into a collective entity and comes to exist as a relationship between agents [Bruni and Stanca 2008). This could be reflected in relational activities being much more dependent on aggregate changes in social participation than private consumption [Antoci et al. 2007)).

The second dimension is that because relational goods are more likely to be related to the identity of agents and the non-instrumental relationship between them, the transmission mechanism by which interactions takes place can be better understood through different intellectual origins. Gui and Sugden [2005], Sugden [2005] and Bruni and Stanca [2008] suggest that Adam Smith's theory of moral sentiments provides an appropriate foundation. The basis of this argument is that relationality is intrinsically connected to the pleasure that people find through being in anothers' company and, in part, this is determined by the affective nature of the relationship, that is, what contributes to agents' moods and emotions [Frey, 2008]. A contrast might be drawn, therefore, between activities such as altruistic or caring behaviour, in which one might act to bring about the goals of other agents, and relationality, because the former behaviour retains an instrumental dimension and the latter can exist simply through experiencing contact with others. As Sugden [2005] argues, from this point of view it is hedonic experiences, as well as preferences that define utility. Consequently relational goods are better understood as drawing upon utility described as being 'experienced' rather than being of a 'decision' form. The latter is associated with an axiomatic approach to choice based purely on preferences 
[Kahneman et al. 1997; Frey, 2008]. In contrast, the former suggests that through the correspondence of sentiments, pleasurable fellow feeling generated by joint activity produces happiness, because social interaction provides an environment in which shared affective states can emerge [Sugden, 2005]. Significantly this suggests that the specific activity or specific characteristics of the individuals are not of sole significance. What matters may be the type of relationship that takes place, or is sought, as an individual undertakes an activity and it is this possibility which forms a central focus of this research, in motivating the exploration of the unobserved heterogeneity of agents in connection with how their activity affects well-being.

\section{$\underline{\text { Empirical work }}$}

As Bechetti et al. [2008] argue, it is primarily in connection with the family and partnerships that the well-being associated with relationships has been investigated. Being married raises well-being compared to being divorced, separated or having suffered bereavement [Gardner and Oswald, 2006). Further, it is shown that becoming married increases well-being levels, which then eventually return to previous levels after about 5 years. In contrast, well-being from the bereavement of a partner only recovers over about an 8 year span [Lucas et al. 2003]. Divorce reduces female well-being more than males, but remarriage can imply a recovery of levels of well-being [Clark et al. 2008; Johnson and Wu, 2002]. Gardner and Oswald [2006] also argue that the reductions in well-being stemming from divorce can be more apparent than real, once one controls for initial higher levels of stress prior to divorce. Further, Stutzer and Frey [2006] argue that there are selection effects that determine household composition. For example, marriage is more likely for happier people. Consequently, Frijters et al. [2008] argue that generally speaking adjustments to relationships have anticipation, selection and adaptation effects.

From a more static perspective, the literature identifies that the well-being of members in a family are positively correlated [Winkelmann, 2005, Shields and Wheatley Price, 2005; Bruhin and Winkelmann, 
2009). De Mello and Tiongson [2009] identify that whilst health is a determinant of well-being, the health of a spouse, if not their children, affects individual well-being, whilst Powdthavee and Vignoles [2008] identify that parental distress can subsequently affect the life satisfaction of children.

The literature examining relationships outside the family is less developed. In an innovative study Blanchflower and Oswald [2004] identify that more regular sex involving fewer partners among higher educated people may be connected with increases in well-being. Further, Powdthavee [2008] has shown that well-being is also generally higher through social interactions, that is, meetings with friends as well as relatives. More broadly Meier and Stutzer [2008] identify that volunteering affects wellbeing positively. Finally, Huang and Humphreys [2012], Forrest and McHale [2011], Downward and Rasciute [2011] and Rasciute and Downward [2010] identify a positive relationship between participation in sports or physical activity and well-being. As well as the physical participation in sport, as leisure, DeLeire and Kalil [2010] identify that compared to other expenditure leisure consumption is associated with an increase in well-being. These are single indicators of relational goods. Importantly, Bechetti et al. [2008] extends this analysis to showing the positive impact of multiple indicators of relational life, such as attending social gatherings, attending cultural events, participating in sports, performing volunteer work, and attending church or religious events on well-being. Finally, extending this work Becchetti et al. [2011] and Becchetti et al. [2012] argue that the time available for collective social leisure, identified through a composite measure of multiple activites, has a positive and statistically significant effect on life satisfaction, and that such a composite measurement of relational goods affect well-being respectively.

A further innovation of these latter two papers is that they attempt to correct for endogeneity in the relationships between consumption of relational goods and subjective well-being. In Becchetti et al. (2011) a -recursive bivariate analysis is adopted to account for the unobserved correlation between the time available for relational activity and subjective well-being derived from the activity. In Becchetti et 
al. (2012) panel data and, in particular, the additional time available as a result of retirement is used to provide an instrumental variable analysis to control for simultaneity between relational good consumption and subjective well-being. The proportion of retirees by age cohort for each year is used as the instrument. This general concern for endogeneity in relational goods is also evident in the analysis of the effect of sport - as a particular example of a relational good - on subjective well-being in the studies by Huang and Humphreys [2012] and Forrest and McHale [2011] noted earlier. In these cases simultaneity between subjective well-being and sports participation is taken accountof by using the supply of sport facilities as an instrument.

An important conclusion of all of these papers is that they reveal that a causal relationship flows from the consumption of relational goods to subjective well-being. In particular, Bechetti et al. [2011] argue that the potential endogeneity of the relational time variables and subjective well-being does not actually affect the substance of single equation estimate results examining how relational time affects subjective well-being. These empirical results suggest that endogeneity may not be of particular importance in examining the relationship between relational goods and subjective well-being. There are also good theoretical reasons for this. As discussed earlier, relational goods in capturing experience from shared fellow feeling, in essence captures a collective entity that is conceptually distinct from the individual and their situation per se. ${ }^{1}$

In this paper, a contribution is offered to extend the literature by examining a unique dataset for England which records the individual's engagement in a number of sporting, arts and cultural activities and events. Such activities can take place in contexts in which such communal and collective experiences can arise. It is important to note here that DeLeire and Kalil [2010] argue that only some of the association of leisure expenditure on well-being could be due to relational experiences. This is because in controlling for the mediation of social connectedness, the size of the leisure consumption

\footnotetext{
${ }^{1}$ Different levels of aggregation also underpin the instruments used in Becchetti et al. (2012).
} 
expenditure coefficient reduces and becomes insignificant. Consequently, they argue that the remaining positive association could reflect conspicuous consumption, for example in the purchase of the latest sporting equipment. However, the insignificance of the coefficients could cast doubt on this interpretation. Moreover, as noted earlier a number of papers identify both causal and associational relationships between the physical participation in sports and leisure activities or attendance at events and well-being. In the current context this is expected to apply. For example, team sports might be expected to be more relational as longer term commitments are involved between participants than in other sports, such as racquet sports, which might involve an opponent but be participated in as an individual. In the same way many arts and cultural activities can be participated in both in front of an audience as well as for individual pleasure, whilst music and theatrical events can be understood as taking place in communal settings, in which the atmosphere is part of the experience. The same could be said of attending live sport events, or activities such as gambling that occurs either at an event like a horse race, or communally in a bingo hall or individually in a betting shop. In general, as these activities are largely discretionary, they at least suggest an ideal opportunity to examine relational behaviour. In this paper the data also allow for the investigation of the impact of the dominant leisure activity of TV viewing. Frey et al. [2007] found that higher levels of TV watching are negatively related to well-being, a result supported by Corneo [2005] and Bruni and Stanca [2008] who argue that it crowds out relational goods.

The main contribution of the paper, however, is that it also investigates unobserved individual heterogeneity by allocating the individuals into a predetermined number of classes to identify if consumption of leisure, arts and cultural activities which might be labelled as relational goods, along with other socio-economic characteristics that can have a relational character, necessarily have a common impact on subjective well-being. It may well be, therefore, that basedon differences in the $r$ associative and instrumental disposition of individuals the effects on well-being could vary across individuals even when undertaking the same sort of activity, or sharing common socio-economic 
circumstances. The reason for this follows directly from a consideration of the essence of relational goods, discussed earlier, which are defined as emanating from the fellow feelings of agents as they engage in activity. It follows that the heterogeneity of the relationship between various activities and well-being is worthy of analysis. Social interactions should be expected to produce groupings of individuals according to their preferences for desirable experiences. An important consequence of this for the paper is that a different empirical strategy is employed to explore unobservables as distinct from those employed as described above and connected with endogeneity. In the latter case, it is possible to make use of (identifying) instruments in the context of selection on unobservables to control for selection bias from the impact on subjective well-being of, say, consumption of a perceived relational good such as sport. This approach logically maintains that no subjective well-being is possible from sport for a non-participant. Alternatively, one might argue that some underlying simultaneity is present between subjective well-being and sport, such that someone who feels happier in life, and perhaps healthier, participates more in sport, as well as sport participation actually contributing to greater subjective well-being, for example via health. Omitted variables such as parental influences on subjective well-being and a procilivity for sports participation might also be suggestive of endogeneity. Leaving aside the empirical findings in the literature discussed above, in principle, in these cases causal effects of the participation in sport on subjective well-being could also be isolated by the use of instrumental variables. These approaches to the analysis of unobservables, however, essentially maintain that a single 'average treatment effect' exists to be identified in the data. In contrast, the current paper explores the possibility that such a relationship is, in fact, heterogeneous and that, say, a sports participant can experience a different level of subjective well-being, or maybe none at all, compared to another participant. This could suggest a difference in motivation or orientation, as a latent characteristic, for different individuals undertaking the same activity and perhaps due to different cultural or life experiences. 
This possibility has only been indirectly investigated in the literature. For example in Rasciute and Downward (2010) it is shown that compared to other forms of physical activity cycling is perceived to contribute towards subjective health but not well-being. There is a trade-off therefore between the motivations of well-being and health. The aim of this paper is to explore this possibility in a much more general way and reflects the manner in which the latent class analysis is conducted as discussed in Section IV.

\section{DATA}

To investigate the relationship between relational activities and individual well-being, the data employed comprises the first tranche of the Taking Part Survey. This is a rolling annual cross-section (not panel) survey commissioned by the Department for Culture Media and Sport and it was conducted by the British Market Research Bureau commencing in 2005 and continues today. ${ }^{2}$ One individual from a randomly sampled household in England was interviewed aged 16 years or older. The first tranche of data comprised of 28,117 respondents.

Well-being in this data is identified by a 'happiness' variable investigated by the question 'Taking all things together, how happy would you say you are?' Respondents then have to assign a value between 1 and 10 to this question with ' 1 ' indicating extremely unhappy and ' 10 ' extremely happy. ${ }^{3}$ The independent variables included in the analysis are based directly upon the determinants identified in the well-being literature and include the personal characteristics of age and its square, gender, ethnicity, education levels, marital status and occupational status. Of particular importance are the identified sports, art and cultural variables which, as argued above, measure relational goods other than the

\footnotetext{
${ }^{2}$ One tranche of data was employed to limit the computational burden placed on the software by estimating the Latent Class Model. As the data series are not part of a panel no loss of opportunity to exploit the heterogeneity in the data is really entailed.

${ }^{3}$ In what follows the happiness categories were merged into three bands to facilitate estimation.
} 
obvious dimensions of married life etc. Each of these goods is measured as a count of the number of activities undertaken and include visits to the library (Library), the number of team sport and non-team sports participated in (NumTSP, NumNTSP), the number or arts and cultural events participated in as an audience member (Audience), the number of arts, cultural, heritage, library and museum visits undertaken (CultVisit), the number of voluntary activities undertaken (NumVoluntary), the number of arts and cultural activities participated in for an audience (NumGrpA), the number of arts and cultural activities undertaken not for an audience (NumA) and the number of gambling activities undertaken in a collective setting (NumGambG). All of the variables and their sample characteristics are summarised in Table 1.

\section{ECONOMETRIC MODEL}

To model the heterogeneous relationship between relational goods and well-being, a two-fold empirical strategy is adopted. First, as is typical of the literature and to assess the robustness of the data for the subsequent latent class analysis, an ordered probit model is estimated on the total sample, producing aggregate results.

Following Greene and Hensher [2010], the random utility model for individual $i$ is:

$$
y_{i}^{*}=\beta^{\prime} x_{i}+\varepsilon_{i}, i=1, \ldots, N .
$$

where the dependent variable represents the underlying latent utility, $y_{i}{ }^{*}$, which is observed in a discrete form through the censoring mechanism:

$$
\begin{aligned}
y_{i} & =0 \text { if } \mu_{-1}<y_{i}^{*} \leq \mu_{0}, \\
& =1 \text { if } \mu_{0}<y_{i}^{*} \leq \mu_{1}, \\
& =2 \text { if } \mu_{1}<y_{i}^{*} \leq \mu_{2}, \\
& =\ldots
\end{aligned}
$$




$$
=\mathrm{J} \text { if } \mu_{J-1}<y_{i}^{*} \leq \mu_{J}
$$

The vector $x_{i}$ is a set of $K$ covariates and $\beta$ is a vector of $K$ parameters. The thresholds, $\mu$, divide the range of utility into cells that are then identified with the observed ratings of happiness.

As discussed in the previous section, the assumption that individuals are homogeneous is potentially unrealistic. It is likely that the effect of various factors on individual well-being will vary across individuals not only due to observed socio-demographic characteristics such as income, age, gender and ethnicity but also because of unobserved (latent) heterogeneity. In particular, as argued earlier, it might be expected that the variety of forms of activities that have the potential to be relational goods could affect well-being differently across economic agents. To account for such potential unobserved heterogeneity two estimation options are available. The first is the latent class (LC) model [Green and Hensher, 2010; Clarke et al. 2005), and the second the random parameters model [Green and Hensher, 2010]. In the latter case parameter values are estimates of the mean and standard deviation of the conditional distribution from which the parameter is drawn, recognising that heterogeneity characterises the (behavioural) parameters. In the former case parameters are distributed discretely. The LC model allows for individual heterogeneity by segmenting economic agents into a predetermined number of classes for which parameters are estimated separately. In this respect the LC model is superior to the random parameter model in that differential associations between the ordered dependent variable can actually be isolated and interpreted rather than just identifying the existence of heterogeneity in effects. Comparison of the collective emphasis of the different associations of the independent variables with the dependent variable from each discrete coefficient vector provides the basis for characterising the unobserved behaviours. Further, the LC model does not require alternative distributions to be chosen for the random parameters, but instead captures individual heterogeneity with a discrete distribution. For these reasons the LC model is employed in this research. 
The LC model approximates the unknown distribution of random coefficients by a finite number of mass points; therefore, simulation is not needed in the estimation process. Individuals are implicitly divided into a predetermined number of classes $C, c=1, \ldots, C$, although it is not known which class contains each individual, though this can be identified after estimation through the use of the estimated probabilities of class membership. Two classes were chosen to allow for the examination of associational and non-associational behaviour; that is a disposition towards relational behaviour or not Two reasons underpin the choice of two classes. On the one hand from a typical welfare economics perspective, theoretically one might expect a twofold difference in behaviours between the consumption (qua definition) of private goods, as represented in typical economic transactions, and club-goods which could be indicative of relational activity as discussed earlier [Cornes and Sandler, 1986]. On the other hand, experimentation with the model revealed that the two class solution was best. This was indicated by a three class version of the model exhibiting very small probabilities of membership of a third-class, coupled with exploding standard errors in the estimates.

Formally the model can be outlined following Greene and Hensher [2010]. Equation 3 describes class membership as distributed with discrete distribution:

$$
\text { Prob (individual } i \text { is a member of class }=c \text { ) }=\pi_{i c}=\pi_{c}
$$

Then equation 4 indicates that the conditional probability of the measured outcomes of the underlying latent utility depends on the joint probability of conditional outcomes for members of a given class and the probability of being in the class.

$$
\operatorname{Prob}\left(y_{i}=j \mid x_{i}\right)=\sum_{c} \operatorname{Prob}\left(y_{i}=j \mid x_{i}, \text { class }=c\right) \operatorname{Prob}(\operatorname{class}=c)
$$

A latent class ordered probit model then describes the probability of outcomes as equation 5:

$$
\operatorname{Prob}\left(y_{i}=j \mid x_{i}\right)=\sum_{c=1}^{C} \pi_{c}\left[\Phi\left(\mu_{j, c}-\beta^{\prime}{ }_{c} x_{i}\right)-\Phi\left(\mu_{j-1, c}-\beta^{\prime}{ }_{c} x_{i}\right)\right]
$$

In the LC model it is possible to use observed characteristics in ' $x$ ' to condition membership of classes. It is important to note here that in the current research and application of the LC model, the membership of the classes was not structured by reference to specific socio-demographic variables as 
the intention was to reveal what was hidden in the data in a more exploratory way and of which these characteristics might reveal important information about an individual's relational dispostion. The two coefficient vectors that are estimated over the same set of independent variables and dependent variable summarise the two discrete relationships that best summarise the data. Whilst individual coefficients in each equation indicate one way, out of two possibilities, in which there is an association between the respective independent variable and well-being, comparing the sign and significance of the sets of coefficients of the independent variables in each of the equations helps to reveal the unobserved heterogeneity of behaviours in much the same way as is normal in Factor analysis. ${ }^{4}$

\section{RESULTS}

All of the empirical results for the paper are presented in tables 2 and 3. In the former case analysis presents the results of the ordered probit model for the whole sample. Subsequent columns of the table then present the disaggregated results to account for observable heterogeneity due to gender and age.

Column 1 of the table presents results that are fully compatible with the well-being literature. It is identified that relative to widowhood, that is bereavement, other forms of marital status are positively related to well-being, with marriage generating the highest impact, which is a result that is common across all of the specifications. ${ }^{5}$ As also identified in the literature, higher income is positively related to well-being as with higher levels of self-reported health. A quadratic age effect is also identified. The age and health results are common across all specifications. Somewhat surprisingly Higher Education is negatively related to overall well-being. This may be evidence of the increased levels of stress associated with the need for self-funding in the UK and is an issue worthy of further investigation. Though there is variance across the specifications, for the total sample unemployment is negatively

\footnotetext{
${ }^{4}$ See for example, Hair,et al [2006]. In Factor analysis, the sign and size of factor loadings, that is correlations between particular variables and the latent constructs to which they are identified, are used to interpret the latent construct.

${ }^{5}$ Strictly the marginal effects are required to make this claim about magnitude. For brevity these are omitted but available from the authors on request.
} 
related to well-being, as described in the literature, and there is some evidence that females feel happier than males, particularly for the middle-aged group. Consistent with the impact of relational goods, the number of adults in the household is generally associated with higher well-being across males, females and all age groups. This suggests that 'company' matters in life.

Heterogeneity starts to appear in the results as one considers the the discretionary activities associated with leisure-time spent on sport, arts and culture. For example, whilst it is shown that the number of team sports participated in is positively associated with well-being for the whole sample, it is evident from the other regressions that this is for younger males. This is a result entirely consistent with sports participation profiles (see Downward et al. 2009). Further, it is evident that viewing sports events live is more likely to be positively related to the well-being of males and the older age-group. Likewise, whilst it is shown that arts and cultural events attended as part of the audience, e.g. theatrical events, dance events, street arts and music events appear to be positively associated with well-being generally, the disaggregated results shows that this applies to females and individuals of the age between 30 and 50 years. Similarly, although arts and cultural exhibitions, heritage activities and museums attended have a positive association with overall well-being, the disaggregated results reveal that this applies to males and individuals over 50 years old. In contrast, volunteering activity is positively associated with the well-being of both males and females but primarily of an older age group. These are impacts that again, coincide with the participation profiles of these activities (Sport England, 2003; DCMS, 2007). In contrast gambling at events, which includes activities such as 'Bingo' are positively associated with the well-being primarily of females. There is also evidence that watching less TV or not watching it at all is positively associated to the well-being of males and those of the older age-group. This suggests that watching TV for older males could be a poor substitute for relational activity as identified in the literature. 
These results are highly suggestive that the relationships between various activities and life events and individual well-being are not just reducible to a single parameter as is implied in the essentially aggregate studies noted in the literature above. Heterogeneity can be observed. However, approaching the heterogeneity of the results in just a deterministic analysis is also limited in the sense that it does not analyse the influences of various socio-demographic characteristics at the same time and, more importantly, it does not take into account any latent (unobserved) heterogeneity of individuals. As discussed above, the literature on relational goods suggests that this might be the case. This has also been suggested in the literature on social-capital formation, for example, that individuals undertaking one form of relational activity are also likely to undertake other forms of such activity. In this respect an underlying 'associational' character might explain variations in the patterns of sport and cultural consumption (Downward et al. 2014; Seippel, 2006; Delaney and Keaney, 2005). To investigate this possibility the Latent Class Ordered Probit (LCOP) model is estimated and the results are presented in Table 3 for the two classes anticipated to exist.

By comparing the sets of estimated coefficients across the two classes, as discussed in Section IV, the estimates for each latent class do appear to support the existence of two different groups of individuals in respect to their associativity, or engagement or experience of relational goods and subjective wellbeing. Whilst both classes, for example, identify that marriage and general health are positively associated with well-being, or that there is a quadratic age-effect, as with the literature generally, some differences occur. Individuals in latent class 1 could be said to exhibit more of a tendency towards instrumental rather than associational activity. This is because variables such as working and higher income are also positively associated with well-being unlike in latent class 2. Significantly too it is non-team sports participation, for example outdoor sports that can often be undertaken in a solitary way or group sports such as racquet sports in which others may be present only as an opponent, that are positively related to well-being for members of this latent class. In contrast, team sports, which involve considerable social commitments and volunteering are positively associated with the well-being of 
members of latent class 2. Furthermore, arts and cultural events attended as part of the audience, e.g. theatrical events, dance events, street arts and music events are also positively related to the well-being of individuals in latent class 2. The same is true of gambling at events, such as bingo. Collectively these results would seem to suggest a more associative disposition of these individuals rather than those of latent class 1.

As is the case with all ordered and binary estimators the values of the estimated parameters are neither comparable across different classes nor have explanatory value on their own due to scale differences. In order to be able to compare the results across different latent classes and to analyse to what degree the well-being of individuals with various unobserved characteristics is, when related to participation in various relational activities, marginal effects have to be estimated. However, marginal effects cannot be estimated for each class separately, as it is not known to which class an individual belongs. In the previous empirical literature that has applied the LC model, only an average effect over all classes is given. In contrast an innovation of this paper is that posterior probabilities are used to identify which individual belongs to which class, and the marginal effects are then estimated for each class separately and given in Table 3 .

For ordered choice models, marginal effects give the impact of covariates on the specific probabilities associated with each category of the dependent variable. The marginal effects must necessarily change sign once following a unit change in the covariate. This shows that the distribution of probabilities of the possible outcomes has changed, known as the single-crossing feature, and means that coefficient signs do not necessarily convey the direction of the impact of the covariate and, of course, the magnitude of the impact because the coefficient has to be scaled by the difference in probabilities of particular outcomes. Nonetheless when covariates enter the model linearly then the sign of the partial effect of the highest value of the ordered dependent variable will coincide with that of the covariate indicating the direction of the effect (Greene and Hensher, 2010). When the utility function is linear in 
parameters, it might be regarded that a positive (negative) coefficient is connected with a reduction (increase) in the probability in the lowest cell and an increase (reduction) in the probability in the highest cell of the dependent variable. With the single crossing feature of the model, such that some probabilities fall and some rise, one can imply that probabilities have shifted in a particular direction.

The results reveal that the probability of belonging to latent class 1 is about 31 percent and latent class 2 correspondingly about 69 percent (Table 3). In general the marginal effects add to the above interpretation by revealing that where variables are significant in both classes, the results tend to emphasise either an associational or instrumental disposition. This is because the marginal effects also allow for a comparison of the size of associations. For example, whilst marriage is positively related to the well-being of both class members, the impact is greater for the associational class 2 . Significantly too, even if the variables have opposite signs, for example with the number of team and sports participated in, the scale of impact is greater for members of latent class 2 than latent class 1 . This suggests that associativity, or its absence, could have greater impacts than more instrumental individual activity. Overall the results are consistent with the idea that associativity can be thought of as an unmeasured effect augmenting or detracting from an individual's well-being per se from engagement in activities that have the potential to allow for experience in relational activity. In this respect the model lends support for the experienced rather than decision utility perspective on individual welfare.

\section{CONCLUSIONS}

The aim of this paper has been to examine the relationship between various activities which could be described as relational goods and the subjective well-being of economic agents, but particularly to focus on those that emanate from sports, arts and cultural activities that are connected with social and associative aspects of life. To achieve this aim ordered choice models are employed on a unique dataset from England. Further the analysis accounts for the likely heterogeneity of these impacts by examining 
both observed and unobserved differences in the characteristics of economic agents. In the former case this is achieved by disaggregating the results according to age and gender that do not have an obvious relational dimension but are factors that are likely to affect participation through the well-being associated with engaging in the activity. The impact of relational goods participation varies with these observable characteristics suggesting the need for caution in interpreting much of the well-being literature that focuses primarily on aggregate results, as expected with the literature.

In the latter case a latent class ordered choice model is employed in order to model unobserved individual heterogeneity. The results suggest that both an associative and an instrumental disposition are identifiable in the data, through the identification of two distinct latent classes. This is consistent with the theoretical arguments connected with relational goods and some empirical claims made in the social capital literature. The signs of the covariates are such as to support the idea that participation in specific activities as relational goods will confer externalities upon individuals, that is participants in them benefit from the participation and presence of others. The marginal effects show greater impacts on their subjective well-being or greater costs from their absence. Overall, the results suggest that experience of associativity from activities which can act as relational goods are an important feature of subjective well-being. Future research should explore this heterogeneity in more detail. 


\section{References}

Antoci, A., Sacco, P.L. and Vanin, P. 2007. Social capital accumulation and the evolution of social participation. Journal of Socio-Economics, 36 (1): 128-143.

Becker, G. 1965. A Theory of the allocation of time. Economic Journal, 75: 493-517

Becker, G. 1974. A Theory of Social Interactions. Journal of Political Economy, 82: 063-1091.

Becchetti, A., Pelloni, A., and Rossetti, F. 2008. Relational Goods, Sociability, and Happiness. Kyklos, 61 (3): 343-363.

Beccheti, L., Trovato, G. and Londono Bedoya, D.A. 2011. Income, relational goods and happiness. Applied Economics, 43: 273-290.

Becchetti, L., Ricca, E.G. and Pelloni, A. 2012. The relationship between social leisure and life satisfaction: causality and policy implications. Social Indicators Research, 108: 453-490.

Blanchflower, D. G. and Oswald, A.J. 2004. Money, Sex and Happiness: An Empirical Study. Scandinavian Journal of Economics, 106 (3): 315-415.

Bruhin, A. and Winkelmann, R. 2009. Happiness Functions with preference interdependence and heterogeneity: the case of altruism within the family. Journal of Population Economics, 22 (4): 10631080 .

Bruni, L. and Stanca, L. 2008. Watching alone: Relational Goods, television, and happiness. Journal of Economic Behaviour and Organisation, 65: 506-528.

Cauley, J. and Sandler, T. 1980. A General Theory of Interpersonal Exchange. Public Choice, 35: 587606.

Clark, A.E. Etile, F. Postel-Vinnay, F. Senik, C and Van der Straeten, K. 2005. Heterogeneity in reported well-being: Evidence from twelve European countries. Economic Journal, 115: C118-C132.

Clark, A.E., Diener, E., Georgellis, Y. and Lucas, R.E. 2008. Lags and Leads in Life Satisfaction: A Test of the Baseline Hypothesis. Economic Journal, 118: F222-F243.

Corneo, G. 2005. Work and television. European Journal of Political Economy, 21(1): 99-113.

Cornes, R. and Sandler, T. 1986. The Theory of Externalities, Public Goods and Club Goods. Cambridge: Cambridge University Press.

Cyert R. M.and March J.G. 1963. A Behavioural Theory of the Firm. Prentice Hall: Englewood Cliffs NJ.

DCMS. 2007. Culture on Demand. London: DCMS.

De Mello, L. and Tiongson, E.R. 2009. What is the Value of (My and My Family's) Good Health. Kyklos, 62 (4): 594-610. 
Delaney, L and Keaney, E. 2005. Sport and Social Capital in the United Kingdom: Statistical Evidence from National and International Survey Data. London: DCMS.

DeLeire, T., and Kalil, A. 2010. Does consumption buy happiness? Evidence from the United States. International Review of Economics, 57:163-176.

Downward, P., Dawson, A. and Dejonghe, T. 2009. Sports Economics: Theory, Evidence and Policy. London: Butterworth-Heinneman.

Downward, P. and Rasciute, S. 2011. Does Sport Make You Happy? An Analysis of the Well-being Derived from Sports Participation. International Review of Applied Economics, 25(3): 331-348

Downward, P., Pawlowski, T. and Rasciute, S. 2013. Does associational behaviour raise social capital? Eastern Economic Journal, forthcoming.

Duesenberry, J. S. 1949. Income, Saving, and the Theory of Consumer Behavior. Cambridge: Harvard University Press.

Frey, B.S. 2008. Happiness: A New Revolution in Economics. MIT Press: Cambridge Massachussetts.

Frey, B.S., Benesch, C. and Stutzer, A. 2007. Does watching TV make us happy? Journal of Economic Psychology, 28: 283-313.

Frijters, P., Johnston, D.W. and Shields, M.A. 2008. Happiness Dynamics with Quarterly Life Event Data. IZA Discussion Paper, No 3604.

Gardner, J. and Oswald, A.J. 2006. Do divorcing couples become happier by breaking up. Journal of the Royal Statistical Society (A), 169 (2): 319-336.

Greene, W.H. and Hensher, D.A. 2010. Modelling Ordered Choices. Cambridge University Press.

Gui, B. 2000. Beyond Transactions: On the Interpersonal Dimension of Economic reality. Annals of Public and Cooperative Economics, 71 (2): 139-169.

Gui, B. and Sugden, R. (eds). 2005. Economics and Social Interaction. Cambridge University press: Cambridge.

Hair, J.F., Black, W. C., Babin, B. J., Anderson, R. E., and Tatham, R. L. 2006. Multivariate data analysis ( $6^{\text {th }}$ ed.). Upper Saddle River, NJ: Pearson/Prentice Hall.

Huang, H. and Humphreys, B.R. (2012). Sports Participation and Happiness: Evidence from US microdata, Journal of Economic Psychology, 33(4): 776-793.

Johnson, D. R. and Wu, J. 2002. An empirical test of crisis, social selection, and role explanations of the relationship between marital disruption and psychological distress: a pooled time-series analysis of four-wave panel data. Journal of Marriage and Family, 64: 211-224.

Kahneman, D., Wakker, P.P., and Sarin, R. 1997. Back to Bentham? Explorations of experienced utility. Quarterly Journal of Economics, 112: 375-405.

Leibenstein, H. 1950. Bandwagon, Snob, and Veblen Effects in the Theory of Consumer's Behavior. Quarterly Journal of Economics, DXIV (2): 183-207. 
Lucas, R. 1976. Econometric Policy Evaluation: A Critique. in The Phillips Curve and Labor Markets, edited by Brunner, K. and Meltzer, A. Carnegie-Rochester Conference Series on Public Policy, 1: 1946.

Lucas, R.E., Clark, A.E., Georgellis, Y. Y. and Diener, E. 2003. Re-examining adaptation and the set point model of happiness: reactions to changes in marital status. Journal of Personality and Social Psychology, 84: 527-539.

Manski, C.F. 1993. Identification of Endogenous Social Effects: The Reflection Problem. The Review of Economic Studies, 60(3): 531-542.

Manski, C.F. 2000. Economic Analysis of Social Interactions. Journal of Economics Perspectives, 14(3): 115-136.

Meier, S. and Stutzer, A. 2008. Is Volunteering Rewarding in Itself? Economica, 75(1): 39-59.

Powdthavee, N. and Vignoles, A. 2008. Mental health of parents and life satisfaction of children: A within-family analysis of intergenerational transmission of well-being. Social Indicators Research, 88( 3): 397-422.

Powdthavee, N. 2008. Putting a price tag on friends, relatives, and neighbours: Using surveys of life satisfaction to value social relationships. Journal of Socio-Economics, 37(4): 1459-1480.

Rasciute, S. and Downward, P.M. 2010. Health or Happiness? What is the Impact of Physical Activity on the Individual. Kyklos, 63(2): 256-270.

Schelling, T. 1971. Dynamic Models of Segregation. Journal of Mathematical Sociology, 1: 143-186.

Schelling, T. A. 1972. Process of Residential Segregation: Neighborhood Tipping. in Racial Discrimination in Economic Life, edited by Pascal, A. Lexington, MA: Lexington Books.

Seippel, O. 2006. Sport and Social Capital. Acta Sociologica, 49(2): 169-183.

Shields, M.A. and Wheatley Price, S. 2005. Exploring the economic and social determinants of psychological well-being and perceived social support in England. Journal of the Royal Statistical Society (A), 168(3): 513-537.

Sport England. 2003. Sports Volunteering in England 2002, Sport England.

Stutzer, A. and Frey, B.S. 2006. Does marriage make people happy, or do happy people get married? The Journal of Socio-Economics, 35: 326-347.

Sugden, R. 2005. Correspondence of Sentiments: An Explanation of the Pleasure of Social Interaction. in Economics and Happiness: Framing the Analysis, edited by Bruni, L. and Porta, P.L. Oxford: Oxford University Press.

Tversky, A. and Kahneman, D. 1974. Judgment Under Uncertainty: Heuristics and Biases. Science, 185: $1124-1131$. 
Veblen, T. 1934. The Theory of the Leisure Class: An Economic Study of Institutions. New York, Modern Library.

Winkelmann, R. 2005. Subjective Well-being and the family: Results from an ordered probit model with multiple random effects. Empirical Economics, 30: 749-761. 
TABLE 1

Variable Descriptions and Descriptive Statistics

\begin{tabular}{|c|c|c|c|c|}
\hline Variable & Freq & $\%$ & $\begin{array}{l}\text { Variable } \\
\text { Type }\end{array}$ & Variable Description \\
\hline Married & 6214 & 0.4824 & Nominal & Married $=1,0=$ otherwise \\
\hline Single & 4233 & 0.3286 & Nominal & Single $=1,0=$ otherwise \\
\hline Separated & 1790 & 0.1390 & Nominal & Separated $=1,0=$ otherwise \\
\hline White & 11002 & 0.8541 & Nominal & White $=1,0=$ otherwise \\
\hline Working & 8556 & 0.6642 & Nominal & Working $=1,0=$ otherwise \\
\hline Student & 423 & 0.0328 & Nominal & Student $=1,0=$ otherwise \\
\hline Retired & 1935 & 0.1502 & Nominal & Retired $=1,0=$ otherwise \\
\hline Unemployed & 396 & 0.0307 & Nominal & Unemployed $=1,0=$ otherwise \\
\hline HE & 5421 & 0.4209 & Nominal & Higher education or equivalent $=1,0=$ otherwise \\
\hline Alevel & 2539 & 0.1971 & Nominal & A Levels $=1,0=$ otherwise \\
\hline Apprentice & 662 & 0.0514 & Nominal & Apprentice $=1,0=$ otherwise \\
\hline Olevel5 & 2417 & 0.1876 & Nominal & 5 GCSEs $=1,0=$ otherwise \\
\hline Gender & 6008 & 0.4664 & Nominal & Male $=1,0=$ female \\
\hline Library & 6955 & 0.5399 & Nominal & Visited a library $=1,0=$ otherwise \\
\hline TVnotWatch & 259 & 0.0201 & Nominal & Did not watch TV $=1,0=$ otherwise \\
\hline TVless1hr & 1070 & 0.0831 & Nominal & Watch TV for less than 1 hour $=1,0=$ otherwise \\
\hline TV1hr & 1710 & 0.1328 & Nominal & Watch TV for about an hour $=1,0=$ otherwise \\
\hline TV2hr & 3730 & 0.2896 & Nominal & Watch TV for about two hours $=1,0=$ otherwise \\
\hline TV3hr & 3021 & 0.2345 & Nominal & Watch TV for about three hours $=1,0=$ otherwise \\
\hline TV4hr & 1733 & 0.1345 & Nominal & Watch TV for about four hours $=1,0=$ otherwise \\
\hline TV5plushr & 1352 & 0.1050 & Nominal & Watch TV for more than five hours $=1,0=$ otherwise \\
\hline \multirow[t]{2}{*}{ Sportlive } & 1980 & 0.1537 & Nominal & $\begin{array}{l}\text { Attended a live sporting event in the last } 4 \text { weeks }=1,0 \\
=\text { otherwise }\end{array}$ \\
\hline & Mean & S.dev & & \\
\hline NumTSP & 0.3038 & 0.7813 & Count & Number of team sports participated in (e.g. rugby, football) \\
\hline NumNTSP & 2.6652 & 2.7345 & Count & $\begin{array}{l}\text { Number of sports other than team participated in (include gym } \\
\text { sports, e.g. keep fit; outdoor sports, e.g. hiking; group sports, } \\
\text { e.g. badminton; and leisure sports, e.g. bowling). }\end{array}$ \\
\hline Audience & 1.5720 & 1.6896 & Count & $\begin{array}{l}\text { Number of arts and cultural events attended as part of the } \\
\text { audience, e.g. theatrical events, dance events, street arts and } \\
\text { cultural events and music events. }\end{array}$ \\
\hline CultVisit & 3.5429 & 2.9357 & Count & $\begin{array}{l}\text { Number of arts and cultural exhibitions, heritage activities and } \\
\text { museums attended. }\end{array}$ \\
\hline NumVolunt & 0.6939 & 1.6351 & Count & Number of volunteering roles undertaken in the last 12 months \\
\hline NumGrpA & 0.2248 & 0.5660 & Count & $\begin{array}{l}\text { Number of arts and cultural activities participated in for an } \\
\text { audience }\end{array}$ \\
\hline NumA & 2.3230 & 1.8784 & Count & $\begin{array}{l}\text { Number of arts and cultural activities participated in not for an } \\
\text { audience }\end{array}$ \\
\hline NumGambG & 0.3061 & 0.6354 & Count & $\begin{array}{l}\text { Number of gambling activities undertaken in a collective } \\
\text { setting }\end{array}$ \\
\hline NumGambI & 0.6041 & 0.5428 & Count & Number of individual gambling activities \\
\hline NumGambE & 0.0634 & 0.2623 & Count & Number of gambling activities in an event \\
\hline Age & 43.5944 & 16.3026 & Cardinal & Age in years \\
\hline Income & 18.1245 & 13.9295 & Cardinal & Total gross annual personal income £000s \\
\hline GenHealth & 4.1016 & 0.8525 & Ordinal & General level of health $5=$ very good to $1=$ very bad \\
\hline NumAdult & 1.9760 & 0.8525 & Count & Number of adults in the household \\
\hline NumChild & 0.6585 & 0.9986 & Count & Number of children in the household \\
\hline
\end{tabular}


TABLE 2

The Ordered Probit Model Results for Separate Groups of Individuals

\begin{tabular}{|c|c|c|c|c|c|c|c|c|c|c|c|c|}
\hline & \multicolumn{2}{|c|}{ Total } & \multicolumn{2}{|l|}{ Male } & \multicolumn{2}{|c|}{ Female } & \multicolumn{2}{|c|}{ Age $<=30$} & \multicolumn{2}{|c|}{$30<$ Age $<=50$} & \multicolumn{2}{|c|}{ Age $>50$} \\
\hline & Coeffs & t-stat & Coeffs & t-stat & Coeffs & t-stat & Coeffs & t-stat & Coeffs & t-stat & Coeffs & t-stat \\
\hline Constant & $-1.16641 * * *$ & -8.95 & $-1.39621 * * *$ & -6.74 & $-1.11912 * * *$ & -6.54 & -9.24651 & 0.00 & $-2.11656 * * *$ & -9.30 & $-1.15109 * * *$ & -7.97 \\
\hline MARRIED & $.50782 * * *$ & 9.09 & $.50336 * * *$ & 5.50 & $.50275 * * *$ & 6.96 & 7.77741 & 0.00 & $.72309 * * *$ & 3.56 & $.37817 * * *$ & 5.74 \\
\hline SINGLE & $.12963 * *$ & 2.19 & 0.15526 & 1.59 & 0.10850 & 1.43 & 7.37452 & 0.00 & $.35867 *$ & 1.77 & 0.07662 & 0.97 \\
\hline SEPARATE & $.19969 * * *$ & 3.38 & $.29574 * * *$ & 2.97 & $.13926 *$ & 1.87 & 7.45973 & 0.00 & $.45305 * *$ & 2.23 & 0.00522 & 0.08 \\
\hline INCOME & $.00202 * *$ & 2.22 & 0.00190 & 1.45 & $.00252 *$ & 1.91 & 0.00356 & 1.61 & $.00360 * * *$ & 2.77 & -0.00121 & -0.74 \\
\hline WHITE & $.09272 * * *$ & 2.97 & $.17817 * * *$ & 3.83 & 0.02385 & 0.56 & $.25348 * * *$ & 4.56 & 0.03606 & 0.82 & -0.05867 & -0.72 \\
\hline WORKING & -0.00399 & -0.11 & 0.09663 & 1.36 & -0.02960 & -0.71 & 0.09211 & 1.28 & -0.05209 & -1.06 & -0.00205 & -0.03 \\
\hline RETIRED & $.18907 * * *$ & 3.51 & $.29248 * * *$ & 3.32 & $.16869 * *$ & 2.32 & & & & & $.28429 * * *$ & 3.97 \\
\hline STUDENT & -0.00653 & -0.10 & $.18545^{*}$ & 1.71 & -0.12349 & -1.32 & $.19776 * *$ & 2.11 & -0.21884 & -1.43 & & \\
\hline UNEMPLOY & $-.30097 * * *$ & -4.37 & $-.18227 *$ & -1.69 & $-.34527 * * *$ & -3.63 & $-.23544 * *$ & -2.09 & $-.30983 * * *$ & -3.01 & -0.21522 & -1.15 \\
\hline $\mathrm{HE}$ & $-.05176 *$ & -1.94 & $-.12302 * * *$ & -3.01 & -0.00855 & -0.24 & 0.00207 & 0.04 & $-.06944 *$ & -1.74 & $-.09323 *$ & -1.96 \\
\hline GENDER & $-.08076 * * *$ & -3.40 & & & & & $-.08645^{*}$ & -1.72 & $-.12657 * * *$ & -3.52 & 0.01496 & 0.36 \\
\hline ALEVEL & -0.00417 & -0.14 & $-.07871 *$ & -1.77 & 0.04062 & 1.03 & 0.04877 & 0.88 & -0.00777 & -0.17 & -0.04957 & -0.89 \\
\hline APPRENTI & $.09210 *$ & 1.86 & 0.03722 & 0.65 & 0.06027 & 0.49 & $-.32291 * *$ & -2.07 & -0.00296 & -0.04 & $.19756 * * *$ & 2.80 \\
\hline AGE & $-.02967 * * *$ & -6.86 & $-.03039 * * *$ & -4.63 & $-.02717 * * *$ & -4.61 & & & & & & \\
\hline AGESQ & $.00036 * * *$ & 7.70 & $.00038 * * *$ & 5.52 & $.00032 * * *$ & 4.95 & & & & & & \\
\hline GENHEALT & $.33819 * * *$ & 25.73 & $.33245 * * *$ & 16.93 & $.33910 * * *$ & 18.88 & $.35241 * * *$ & 11.98 & $.38008 * * *$ & 18.69 & $.28638 * * *$ & 13.07 \\
\hline NUMADULT & $.07267 * * *$ & 5.17 & $.07581 * * *$ & 3.72 & $.06912 * * *$ & 3.52 & $.08052 * * *$ & 3.72 & $.08679 * * *$ & 3.52 & $.05936 *$ & 1.71 \\
\hline NUMCHILD & 0.00779 & 0.65 & 0.02717 & 1.46 & -0.00068 & -0.04 & $.05185 * *$ & 2.00 & 0.01105 & 0.73 & $-.10845 * *$ & -1.96 \\
\hline NUMTS & $.03661 * *$ & 2.32 & $.04793 * *$ & 2.49 & 0.01686 & 0.53 & $.06419 * * *$ & 2.81 & 0.02146 & 0.84 & 0.06347 & 0.91 \\
\hline NONTSP & 0.00244 & 0.52 & -0.00121 & -0.19 & 0.00612 & 0.87 & 0.00624 & 0.74 & 0.00406 & 0.61 & -0.00661 & -0.60 \\
\hline AUDIENCE & $.01915 * *$ & 2.52 & 0.00448 & 0.39 & $.02902 * * *$ & 2.86 & 0.02373 & 1.33 & $.02843^{* *}$ & 2.52 & 0.00314 & 0.25 \\
\hline CULTVISIT & $.00990 * *$ & 2.11 & $.01206 *$ & 1.79 & 0.00867 & 1.32 & 0.00111 & 0.10 & 0.00694 & 1.00 & $.01726 * *$ & 2.14 \\
\hline NUMGRPA & 0.01914 & 0.99 & 0.04523 & 1.47 & 0.00248 & 0.10 & 0.03346 & 0.93 & $.05397^{*}$ & 1.76 & -0.03834 & -1.09 \\
\hline NUMA & -0.00862 & -1.30 & -0.01332 & -1.30 & -0.00638 & -0.73 & -0.00557 & -0.41 & $-.01787 *$ & -1.81 & 0.00523 & 0.43 \\
\hline LIBRARYD & $-.06933 * * *$ & -3.20 & $-.07371 * *$ & -2.31 & $-.06223 * *$ & -2.09 & -0.07190 & -1.58 & -0.04022 & -1.24 & $-.10622 * * *$ & -2.74 \\
\hline NUMVOLT & $.01659 * *$ & 2.51 & $.01965 * *$ & 2.09 & $.01565 *$ & 1.67 & -0.01381 & -0.74 & 0.00069 & 0.06 & $.04125 * * *$ & 4.29 \\
\hline TVNOTWAT & $.14362 *$ & 1.91 & $.20573 * *$ & 1.98 & 0.08172 & 0.74 & 0.12393 & 0.90 & 0.05666 & 0.47 & $.27792 * *$ & 1.99 \\
\hline TVLESS1H & 0.06280 & 1.47 & $.12024 *$ & 1.95 & 0.01003 & 0.17 & -0.01705 & -0.20 & 0.09516 & 1.51 & 0.12303 & 1.47 \\
\hline TV1HR & -0.02072 & -0.57 & 0.02654 & 0.49 & -0.05954 & -1.20 & $-.15189 * *$ & -2.06 & 0.02196 & 0.40 & 0.03934 & 0.57 \\
\hline TV2HR & 0.00737 & 0.25 & 0.01054 & 0.24 & 0.00101 & 0.03 & -0.05306 & -0.89 & 0.04389 & 0.96 & 0.01705 & 0.34 \\
\hline
\end{tabular}




\begin{tabular}{|c|c|c|c|c|c|c|c|c|c|c|c|c|}
\hline TV3HR & -0.01295 & -0.43 & -0.00663 & -0.15 & -0.01833 & -0.45 & -0.04644 & -0.75 & 0.06268 & 1.31 & -0.07564 & -1.51 \\
\hline SPORTLIV & 0.04167 & 1.44 & $.06923 *$ & 1.80 & -0.00024 & -0.01 & 0.07955 & 1.33 & -0.00639 & -0.16 & $.09860 *$ & 1.72 \\
\hline NUMGAMBI & 0.02743 & 1.38 & 0.04350 & 1.53 & 0.01361 & 0.49 & 0.01340 & 0.32 & 0.00030 & 0.01 & 0.02919 & 0.82 \\
\hline NUMGAMBG & -0.00213 & -0.12 & 0.00546 & 0.24 & -0.00993 & -0.37 & -0.00990 & -0.34 & 0.01200 & 0.47 & -0.01749 & -0.44 \\
\hline NUMGAMBE & 0.05422 & 1.36 & 0.00339 & 0.06 & $.11278 *$ & 1.85 & 0.10604 & 1.27 & 0.00455 & 0.08 & 0.12700 & 1.53 \\
\hline \multicolumn{13}{|c|}{ Thres } \\
\hline $\mathrm{Mu}(1)$ & $.84527 * * *$ & 71.38 & $.85822 * * *$ & 49.07 & $.83740 * * *$ & 51.84 & $.83693 * * *$ & 34.17 & $.88740 * * *$ & 48.96 & $.80340 * * *$ & 39.16 \\
\hline
\end{tabular}


TABLE 3

The Latent Class Model Results

\begin{tabular}{|c|c|c|c|c|c|c|}
\hline & \multicolumn{2}{|c|}{ Class I } & \multicolumn{2}{|c|}{ Class II } & Class I & Class II \\
\hline & Coeffs & t-stat & Coeffs & t-stat & \multicolumn{2}{|c|}{ Marginal Effects } \\
\hline Constant & $-2.08454 * * *$ & -3.13 & $-1.02147 * * *$ & -4.25 & & \\
\hline MARRIED & $.69545 * * *$ & 2.92 & $.55243 * * *$ & 5.83 & 0.06721 & 0.21154 \\
\hline SINGLE & 0.19586 & 0.80 & 0.15549 & 1.59 & 0.01942 & 0.06039 \\
\hline SEPARATE & 0.16824 & 0.70 & $.26673 * * *$ & 2.72 & 0.01741 & 0.10479 \\
\hline INCOME & $.02332 * * *$ & 3.77 & $-.00400 *$ & -1.70 & 0.00217 & -0.00154 \\
\hline WHITE & $.83615^{* * *}$ & 3.87 & -0.07159 & -1.15 & 0.04962 & -0.02782 \\
\hline WORKING & $.34423 * *$ & 2.00 & -0.08946 & -1.48 & 0.02908 & -0.03467 \\
\hline RETIRED & 0.31583 & 1.38 & $.18410 * *$ & 2.06 & 0.03562 & 0.07204 \\
\hline STUDENT & 0.33929 & 1.05 & -0.11087 & -0.90 & 0.04111 & -0.04219 \\
\hline UNEMPLOY & -0.47867 & -1.45 & $-.32842 * * *$ & -3.04 & -0.03026 & -0.12015 \\
\hline $\mathrm{HE}$ & -0.13422 & -1.08 & -0.03577 & -0.74 & -0.01238 & -0.01381 \\
\hline GENDER & -0.03802 & -0.34 & $-.10694 * *$ & -2.46 & -0.00353 & -0.04126 \\
\hline ALEVEL & $-.24280 *$ & -1.75 & 0.05573 & 1.03 & -0.01992 & 0.02162 \\
\hline APPRENTI & 0.16633 & 0.71 & 0.06673 & 0.73 & 0.01762 & 0.02596 \\
\hline AGE & $-.07285 * * *$ & -3.34 & $-.02619 * * *$ & -3.24 & -0.00679 & -0.01012 \\
\hline AGESQ & $.00071^{* * *}$ & 3.28 & $.00036^{* * *}$ & 4.18 & 0.00007 & 0.00014 \\
\hline GENHEALT & $.39054 * * *$ & 5.50 & $.36912 * * *$ & 14.60 & 0.03638 & 0.14260 \\
\hline NUMADULT & 0.10563 & 1.54 & $.07328 * * *$ & 2.83 & 0.00984 & 0.02831 \\
\hline NUMCHILD & -0.02758 & -0.50 & 0.01840 & 0.87 & -0.00257 & 0.00711 \\
\hline NUMTS & $-.16298 * *$ & -1.96 & $.09805 * * *$ & 2.93 & -0.01518 & 0.03788 \\
\hline NONTSP & $.10653 * * *$ & 3.61 & $-.02905 * *$ & -2.26 & 0.00992 & -0.01122 \\
\hline AUDIENCE & -0.00876 & -0.25 & $.02795^{*}$ & 1.95 & -0.00082 & 0.01080 \\
\hline CULTVISIT & $.05034 * *$ & 2.12 & 0.00095 & 0.11 & 0.00469 & 0.00037 \\
\hline NUMGRPA & 0.09904 & 1.06 & 0.00130 & 0.03 & 0.00923 & 0.00050 \\
\hline NUMA & -0.02294 & -0.74 & -0.00604 & -0.49 & -0.00214 & -0.00234 \\
\hline LIBRARYD & -0.04528 & -0.45 & $-.08902 * *$ & -2.25 & -0.00424 & -0.03441 \\
\hline NUMVOLT & -0.02617 & -0.92 & $.03061 * *$ & 2.51 & -0.00244 & 0.01183 \\
\hline TVNOTWAT & 0.22341 & 0.67 & 0.12497 & 0.97 & 0.02492 & 0.04890 \\
\hline TVLESS1H & -0.10497 & -0.55 & 0.13071 & 1.64 & -0.00908 & 0.05109 \\
\hline TV1HR & -0.08869 & -0.54 & 0.00074 & 0.01 & -0.00782 & 0.00029 \\
\hline TV2HR & 0.08278 & 0.63 & -0.00879 & -0.17 & 0.00794 & -0.00340 \\
\hline TV3HR & 0.19339 & 1.35 & -0.07442 & -1.34 & 0.01975 & -0.02859 \\
\hline SPORTLIV & 0.13608 & 0.93 & 0.01634 & 0.29 & 0.01371 & 0.00632 \\
\hline NUMGAMBI & -0.04371 & -0.47 & 0.05690 & 1.54 & -0.00407 & 0.02198 \\
\hline NUMGAMBG & 0.07657 & 0.87 & -0.02606 & -0.77 & 0.00713 & -0.01007 \\
\hline NUMGAMBE & $-.42228 * *$ & -2.09 & $.19928 * *$ & 2.44 & -0.03933 & 0.07699 \\
\hline MU(1) & $1.87756 * * *$ & 5.46 & $.65001 * * *$ & 10.94 & & \\
\hline Class1Pr & $.31409 * * *$ & 4.57 & .6859 & 9.99 & & \\
\hline
\end{tabular}


